\title{
Estratégias de Consumo em Saúde entre Famílias Trabalhadoras ${ }^{1}$ \\ Strategies for Consumption of Health Care by Working-Class Families
}

\author{
Marcos S. Queiroz ${ }^{2}$
}

QUEIROZ, M. S. Strategies for Consumption of Health Care by Working-Class Families. Cad. Saúde Públ., Rio de Janeiro, 9 (3): 272-282, jul/sep, 1993.

This article analyzes representations and practices regarding health and illness among workingclass families in Paulínea, São Paulo. Special emphasis is placed on the relationship with the medicine employed by doctors in the network of public health care services recently implemented in the town and considered by health care experts to be a model in the Brazilian context. The study also focuses on practices related to traditional household or religious medicine and medication by pharmacists as important elements available to the families studied.

Key words: Health and Disease Representations; Primary Health Care; Worker's Health; Health Services

\section{INTRODUÇÃO}

Este artigo analisa as estratégias e as representações sobre saúde e doença, com ênfase no relacionamento com a medicina posta em prática pela rede pública de atenção à saúde entre famílias operárias do município de Paulínea, São Paulo. O contexto desta pesquisa envolve um amplo contingente de imigrantes provenientes do mundo rural que se defrontam com a disponibilidade de serviços públicos de saúde considerados modelo para a realidade brasileira. Foram também entrevistados 11 médicos da rede pública, 2 médicos da rede privada, 14 farmacêuticos, 2 enfermeiros, 3 atendentes de enfermagem e 4 benzedores. A pesquisa foi conduzida durante os anos de 1988 e 1989 como parte de um projeto maior que redundou na publicação de um livro (Queiroz, 1991). O presente artigo baseia-se em informações contidas neste livro.

\footnotetext{
${ }^{1}$ Pesquisa conduzida com recursos da Financiadora de Estudos e Projetos e uma Bolsa de Pesquisa do Conselho Nacional de Desenvolvimento Científico e Tecnológico. ${ }^{2}$ Núcleo de Estudos de Políticas Públicas da Universidade Estadual de Campinas. Cidade Universitária Zeferino Vaz. Campinas, SP, 13084-100, Brasil.
}

\section{AS FAMÍLIAS PESQUISADAS}

Foram pesquisadas 42 famílias em dois bairros de Paulínea, totalizando 52 indivíduos. Destes, 42 eram mulheres e 10, homens. As duas primeiras entrevistas foram tomadas ao acaso, na sala de espera dos Postos de Saúde de cada um destes bairros, enquanto as entrevistas seguintes foram conduzidas a partir da rede social destes dois indivíduos. Estas famílias foram acompanhadas durante 1 ano, checandose e contrachecando-se as informações dentro do princípio qualitativo apropriado para uma situação de pequena escala, de acordo com a tradição antropológica.

A unidade residencial da grande maioria destas 42 famílias é constituída basicamente de pai, mãe e filhos, sendo também comum encontrar agregados tais como sogro, sogra, genro, nora e netos (cerca de 25\%). A idade média dos representantes (marido e mulher) de cada família é de 38 anos. Nestas famílias, o número total de filhos que ainda residem com seus pais é 87 , o que significa uma média de 2,07 filhos por família, média esta relativamente baixa, apontando uma grande freqüência do uso de métodos anticoncepcionais e, principalmente, entre estes, do método de esterilização feminina. 
A maioria dos chefes de família trabalha nos estabelecimentos industriais de Paulínea, ou como operários com um grau incipiente de especialização, ou em serviços autônomos. Apenas 10 donas de casa têm um emprego regular fora de casa, embora um número maior delas costuma realizar pequenos serviços esporádicos ("bicos"). A renda familiar da grande maioria (31) dos entrevistados varia entre 3 e 8 salários mínimos. Uma minoria de três famílias conta com uma renda menor e oito com uma renda maior. A média de rendimento de todas as famílias estudadas, sem se considerar os agregados, é de 5 salários mínimos.

A grande maioria da população é constituída de migrantes, sendo que $52 \%$ são procedentes de outros estados (principalmente Minas Gerais, Paraná e estados do Nordeste) e 48\%, do interior do estado de São Paulo. Apenas uma minoria é natural do município de Paulínea propriamente dito. Considerando apenas a população adulta maior de 21 anos, $47 \%$ são provenientes do meio rural. A média de tempo de residência nos bairros estudados, levando-se em conta apenas o chefe da família e a dona de casa, é de 9 anos. De modo geral, as representações sobre a cidade, o bairro e os serviços públicos por parte destas famílias são bastante favoráveis em relação ao local de procedência.

\section{O SIGNIFICADO DA SAÚDE E DA DOENÇA}

Para a grande maioria desta população, estar doente não significa um evento exclusivamente biológico, projetando-se no efeito mais dramático que produz, qual seja, a incapacidade de trabalhar e a consequiente ameaça à subsistência familiar. Deste modo, se um indivíduo mostra disposição e capacidade de trabalho, ele é considerado saudável. Só num segundo plano a boa aparência e a disposição para sair e passear aparecem como definidores adequados de saúde para indivíduos adultos, embora estas predominem quando se tratam de crianças. Em função deste tipo de representação, uma das entrevistadas, com um quadro clínico de diabetes, reumatismo, complicações renais e hipertensão arterial, considerou-se uma pessoa saudável no momento da entrevista, uma vez que ainda encontrava forças para executar todas as atividades domésticas.

Uma interpretação bastante plausível para este fenômeno foi fornecida por Boltanski (1979), ao mostrar que, entre as classes sociais mais baixas, a doença tenderia a ser percebida somente quando houvesse uma incapacitação do desempenho social, representada principalmente pelo trabalho. Sem surpresa, observamos que estes resultados repetem os de outras pesquisas realizadas em diferentes contextos (Giovani, 1980; d'Hautand \& Fieldman, 1984). Estes trabalhos demonstram que, entre camadas de trabalhadores manuais, a noção de saúde envolve, necessariamente, integração à sociedade, através do cumprimento de tarefas entendidas como obrigatórias. Nesta concepção, a idéia de saúde é alienada do indivíduo e apropriada pelo meio social via capacidade de trabalho, exatamente o contrário do que ocorre entre as camadas sociais superiores.

Devido ao fato de, nos últimos 15 anos, a medicina oficial ter se tornado cada vez mais disponível a esta população, principalmente através da rede pública de serviços de saúde, não foi possível encontrar uma única família que não fizesse uso corrente dos serviços médicos. Os entrevistados mostraram-se totalmente familiarizados com consultas médicas, nomes de doenças e medicamentos. Em particular, destaca-se o recurso a cirurgias. Foram reportadas 21 cirurgias nas 42 unidades familiares pesquisadas, excluindo-se as cesarianas e as esterilizações. O número de esterilizações (19) também é bastante significativo.

Em geral, a dona de casa é, na famíllia, a personagem principal no trato de questões de saúde e doença. De forma quase unânime, é ela quem avalia as condições de saúde, tanto a sua própria como a de seus filhos, e toma a decisão de procurar os agentes de cura considerados necessários para cada caso de doença. À pergunta "Quem mais entende de saúde e de doença na família?", a mãe ou a dona de casa foi a resposta fornecida em $77 \%$ dos casos. Em geral, o chefe de família, ou o pai, permanece distante destes assuntos, principalmente porque fica a maior parte do tempo longe da residência e, muitas vezes, recebe assistência médica na própria firma em que trabalha.

Os nossos dados revelam, também, que a 
mulher percebe sintomas de doenças muito mais do que o homem, assim como procura mais intensamente por soluções dentro ou fora do âmbito da medicina oficial, tanto para ela como para seus filhos. Portanto, o contato que a mulher mantém com os agentes da medicina oficial (médicos, enfermeiras, atendentes e farmacêuticos) e da medicina popular religiosa (benzedores, pais ou mães-de-santo, padres ou pastores) é muito mais freqüente do que aquele que ocorre com o homem. Deste modo, ela se expõe a todo um universo que pressupõe várias linguagens e modos de perceber, classificar e agir sobre certos sinais e sintomas corporais.

Boltanski (1979) chama a atenção para o fato de a linguagem, o conceito e o nome serem indispensáveis para a percepção de um sintoma. Da mesma forma, a Antropologia tem demonstrado que aquilo que não é classificado nem nomeado pela cultura também não é percebido. Assim, num contexto em que os homens fazem pouco uso dos serviços de saúde oficiais e populares, como é o caso da população estudada nesta pesquisa, é de se esperar pouca familiaridade com a linguagem que configura tanto o problema como as vias que conduzem à sua solução. $\mathrm{O}$ trecho seguir extraído de uma das entrevistas, revela bem a representação encontrada entre as famílias pesquisadas:

\section{- "Quem entende de saúde na família sou eu} mesma. Meu marido não entende nada. Não costumo deixar nem remédio para ele dar para as crianças, porque é capaz de trocar tudo". (Operária, 27 anos)

No que diz respeito à causação de doenças, a população pesquisada revela possuir várias noções, que são mostradas com maior ou menor grau de elaboração e sistematização. Um aspecto dos mais importantes, neste sentido, refere-se ao fator nervosismo, principalmente para a mulher. Associado às preocupações de toda sorte e às frustrações, que envolvem tanto as situações particulares de vida restritas à família como aquelas mais gerais, relacionadas com a instabilidade econômica e social, o nervosismo foi apontado como o principal agente causador de doenças. Outro fator também apontadoo como importante na causação de doenças diz respeito a uma idéia fatalista relacionada com destino, Deus ou natureza. Em menor intensidade, mas ainda com alguma relevância, aparecem os conceitos de alimentação insuficiente, falta de higiene e condições climáticas adversas. Finalmente, em proporção bem menor, aparecem fatores relacionados com os excessos provenientes de uma vida desregrada, principalmente a bebida alcoólica.

\section{REPRESENTAÇÕES E PRÁTICAS SOBRE MEDICINA POPULAR}

Para os propósitos desta pesquisa, definimos medicina popular como sendo todas as representações e práticas relativas à saúde e à doença que se manifestam independentemente do controle da medicina oficial, ou seja, aquela medicina institucionalizada e regulamentada pelo poder público constituído. É possível encontrar duas áreas distintas onde se manifesta a medicina popular: a medicina caseira, baseada principalmente nas ervas medicinais, e a medicina religiosa, baseada principalmente na benzedura. Outras medicinas alternativas, como, por exemplo, a osteopatia, a macrobiótica e a acumpuntura, não são sequer conhecidas pela população. A homeopatia, no entanto, já foi usada pelo menos uma vez por $30 \%$ da população, sendo, no entanto, um recurso eventual e esporádico.

Estas duas áreas - a medicina caseira e a medicina religiosa - são de uso comum e generalizado entre os entrevistados. Apenas duas famílias reportaram não empregar normalmente ervas medicinais, e somente quatro relataram que, por princípio, não recorrem, nem nunca recorreram, a benzedores.

\section{A Medicina Caseira}

As ervas medicinais, termo genérico que compreende várias qualidades de plantas ou partes de plantas, tais como raízes, folhas, troncos de árvore e sementes, são consideradas de efeito terapêutico, sendo usadas principalmente como chás, para uso interno, e, num plano secundário, como banhos ou ungüentos, para aplicação externa. Elas são consumidas como parte importante no cuidado doméstico com a saúde e como estratégia empregada 
principalmente pela dona de casa no trato de alguns sintomas e doenças de seus filhos.

Embora no interior rural do país existam especialistas neste tipo de medicina, como os raizeiros profissionais, que, além de comercializarem medicamentos naturais, ainda oferecem consulta, em Paulínea não se verificou a existência deste tipo de agente, embora existam pessoas que se consideram entendidas no assunto e que prestam efetiva assistência à comunidade.

Há relatos mostrando que a prática deste tipo de medicina, no mundo rural latino-americano, em geral (Foster, 1976), e brasileiro, em particular (Queiroz, 1984), ocorre obedecendo a uma lógica que classifica medicamentos naturais e alimentos como "quente" e "frio". No entanto, em contextos urbanos e industrializados, esta lógica classificatória, baseada principalmente no reconhecimento de que a saúde seria promovida por um equilíbrio do organismo humano com seu meio externo, intermediado principalmente pela alimentação, tende a ser perder em favor de um princípio mais sintomático, que, da mesma maneira como ocorre com a prática da medicina oficial, procura intervir mais dramática e diretamente no organismo humano, no sentido de rapidamente aliviar os sintomas que incomodam o paciente e restabelecer a sua capacidade de trabalho. Assim, neste contexto, o consumo da medicina caseira aproxima-se, em muitos aspectos, do consumo de medicamentos industrializados e, em várias ocasiões, faz-se em sintonia e em associação com estes últimos.

A razão da persistência destes medicamentos num contexto capitalista relativamente desenvolvido é que eles, até certo ponto, complementam os vazios deixados pela medicina oficial, como, por exemplo, os "mal-estares" e indisposições consideradas não-graves, ou algumas doenças crônicas para as quais os médicos previdenciários, ou os de postos de saúde em geral, deixam de medicar, principalmente porque não existem meios de cura simples disponíveis.

A grande maioria dos que consomem ervas medicinais as cultiva no quintal próprio ou as obtem de vizinhos, haavendo apenas uma minoria que as adquire exclusivamente em farmácia, mercado ou feira. As ervas e produtos medicinais mais empregados são o boldo, o poejo, a hortelã e a folha de abacate, para problemas do fígado e do intestino; a quebrapedra, para problemas dos rins; o alho e o mel, para gripes e resfriados; a camomila, para cólicas menstruais; a erva-cidreira, para a insônia e problemas nervosos; e a erva-doce, para problemas estomacais.

A difusão do conhecimento que envolve a medicina caseira ocorre principalmente através de pessoas mais velhas na família, geralmente via sexo feminino, embora o sexo masculino não seja excluído, havendo alguns que efetivamente se interessam por este assunto. Nos bairros pesquisados foram encontradas três mulheres que se consideram, e são consideradas, especialistas em ervas medicinais e que prestam assistência à população, diagnosticando doenças e recomendando tratamentos. $\mathrm{O}$ espiritismo kardecista e, mais modernamente, a umbanda são também importantes difusores das ervas medicinais e das formas terapêuticas que elas envolvem.

Em geral, a medicina caseira não contradiz nem se conflitua com a medicina oficial, na medida em que, na grande maioria dos casos, ela não se coloca como uma alternativa, mas apenas como um complemento limitado. No entanto, muitos reconhecem que a sua terapia, embora lenta, é mais saudável, porque não envolve uma intervenção drástica no organismo e não deixa seqüelas. Em algumas ocasiões, no entanto, em favor da modernidade, algumas famílias recusam o consumo de tudo que denote tradição, neste caso associada a atraso e ignorância.

\section{A Medicina Religiosa}

A postura que procuramos empregar ao analisarmos a medicina religiosa em Paulínea tem como marco teórico Bourdieu (1975), que, num contexto capitalista, percebe o campo religioso em geral como um mercado de bens simbólicos, cujo consumo não exige necessariamente um comprometimento ético. Desta maneira, a religião transforma-se em mercadoria que, num sistema competitivo de mercado, é vendida não em sua totalidade, mas como um instrumento parcial para problemas pessoais parciais. 
No Brasil, Montero (1985) estudou o fenômeno da grande expansão de clientelas flutuantes e transitórias que combinam a eficácia de produtos de empresas de tradições diferentes, senão antagônicas. Como mercadoria, a religião passa a desempenhar uma função utilitária, que serve como instrumento para atenuar as aflições em geral da vida urbana. Assim, a clássica função das religiões, isto é, a construção de mundos com sentido, analisada por Weber (1969), é suplantada pela função de controle das incertezas num mundo sem estabilidade, em constante processo de mudança.

As principais instituições religiosas que tratam de problemas de doença em Paulínea são o espiritismo kardecista; a umbanda; algumas seitas protestantes, como o pentecostalismo; o catolicismo brasileiro; e o catolicismo romano popular, que se manifesta através de grupos de reza. Uma das práticas mais difundidas da medicina religiosa ocorre através do relacionamento com as benzedeiras e benzedores, que utilizam-se das tradições rituais do catolicismo popular e do espiritismo kardecista para prestarem assistência à população.

Apesar do grande prestígio que a medicina oficial usufrui atualmente junto às camadas sociais trabalhadoras, ela não é considerada plenamente adequada para certas disfunções, como, por exemplo, certas doenças infantis, algumas doenças crônicas de difícil tratamento e doenças ou mal-estares psiquiátricos em geral.

Freqüentemente recorre-se a benzedura para as crianças. Para o adultos, a benzedura é mais comum entre as mulheres, sendo que, entre os homens, ela se restringe a ocasiões especiais, como, por exemplo, em casos de grande aflição não só por causa de doenças, mas também por problemas de vida em geral. As entrevistas transcritas abaixo revelam bem como o recurso à benzedura é representado pela comunidade.

\section{- "Quando percebo que meus filhos estão}

nervosos, sei que devo levá-los ao benzedor, porque eles sempre melhoram depois do "benzimento". Para a criança, o benzedor é necessário para coisas como susto, quebranto, bucho virado, cobreiro e outras poucas coisas mais, enquanto o médico é para todo o resto".

(Dona de casa, 26 anos)
- "Qualquer doença pode ser benzida, mas é preciso fé e um benzedor que benze mesmo, porque esses por aí só dizem que curam e nem sempre curam de verdade. Graças a Deus eu nunca fui a centros espíritas ou de umbanda, porque eles só estão interessados em dinheiro. Eu acho que a gente vai nesses lugares quando tem uma doença que não consegue resolver $e$ só em último caso. Eu tenho uma certa cisma de benzedores, porque há dois tipos deles: os que só fazem coisas boas e os que fazem mal, e é desse último tipo que eu tenho medo".

(Dona de casa, 27 anos)

Vemos claramente, nessas entrevistas, que a benzedura apresenta um elemento ambíguo, principalmente quando ela se refere a problemas de adultos e é tratada por agentes ligados a centros espíritas ou de umbanda. Se há um crédito na eficácia do produto, ao mesmo tempo ele é considerado uma força fora de controle dos padrões morais da sociedade, uma vez que pode se dirigir tanto para o bem como para o mal. Daí o cuidado que deve-se tomar na escolha do benzedor. Quando, no entanto, trata-se de um caso reconhecido de doença cujo tratamento não tem sido bem-sucedido pelos meios oficiais, ou quando desconfia-se de que se está sendo vítima de inveja, mau-olhado ou feitiço, então o consumo de benzedores, principalmente pelas mulheres, é freqüente, mesmo os de reputação duvidosa, geralmente também considerados com poderes sobrenaturais maiores.

Quando o paciente é uma criança, no entanto, o consumo da benzedura é considerado perfeitamente legítimo e socialmente aceitável. Mesmo os que não acreditam muito na sua eficácia levam seus filhos para benzer, por via das dúvidas e pela pressão social favorável.

\section{A MEDICINA OFICIAL E SEUS AGENTES}

A oferta de serviços de saúde "oficial" para a população estudada nesta pesquisa compreende, basicamente, a rede básica de serviços públicos de saúde, os farmacêuticos, a medicina conveniada e a medicina privada, envolvendo agentes tais como médicos, enfermeiras, atendentes de enfermagem e práticos de farmácia.

A medicina conveniada é realizada pelas grandes firmas que, por este meio, provêm 
cuidados médicos aos seus funcionários e suas famílias. Estima-se que cerca de 1.800 trabalhadores e suas famílias estejam cobertos por este sistema, que recebe da comunidade uma avaliação bastante positiva em relação ao sistema público. Já o consumo da medicina particular, através de consulta privada, embora receba aprovação inquestionável da comunidade pesquisada, é um recurso que, pelo seu custo financeiro, torna-se excepcional.

Por serem as instâncias mais importantes nas estratégias de consumo em saúde das famílias pesquisadas, concentraremos a análise na medicina pública e nas farmácias do município.

\section{A Medicina e os Médicos do Setor Público}

Com um centro de saúde, três postos de saúde e um hospital municipal com capacidade para 100 leitos, a rede básica de serviços públicos de saúde é, atualmente, a principal referência de consumo em saúde para a população pesquisada. Esta rede tem sido organizada e administrada pela Unicamp desde 1977, em convênio com a prefeitura do município. A compreensão do significado da medicina posta em prática por esta rede requer um pequeno comentário sobre os principais aspectos da postura assumida pelos seus médicos.

A medicina do setor público em Paulínea, em contraposição à medicina privada, percebe os fatores sócio-econômicos e culturais como instâncias importantes na determinação da doença e do nível de saúde de uma população. O paciente é, então, percebido não como um agente isolado, mas como membro de uma comunidade que com ele partilha experiências sociais comuns. Já a doença é percebida como o resultado de problemas multicausais relacionados com o modo de vida, tomado num sentido amplo, no qual o organismo biológico é visto como um todo maior que a soma de seus órgãos e estruturas. Assim, ao invés de exigir um especialista numa determinada estrutura biológica do organismo humano, o ato terapêutico requer uma equipe multidisciplinar para tratar o paciente. Neste esquema, a prestação de serviços de saúde à população deve ser gerenciada pelo Estado, no sentido de evitar desperdícios, bem como a duplicidade e inadequação de tratamentos médicos.
A prática terapêutica promovida por estes médicos procura, via de regra, estimular a recuperação espontânea do organismo, antes de intervir com medicamentos mais poderosos. Ainda que esta forma de tratamento exija mais tempo para o restabelecimento, há um consenso de que ela é mais segura e eficiente, porque induz o paciente a reconhecer melhor aquilo que, no seu dia a dia, produz equilíbrio e, consequientemente, saúde. Além disso, este método gera muito menos riscos e efeitos colaterais.

Não é surpresa constatar que esta postura choca-se com a medicina hegemônica praticada no país, influenciada pelas indústrias farmacêutica e hospitalar. No entanto, o choque mais visível e imediato ocorre com relação a uma ampla parcela da população, que, sugestionada pela propaganda e pelas promessas de curas milagrosas, reivindica justamente uma medicina baseada no hospital e na abundância de medicamentos químicos e equipamentos de alta tecnologia.

Embora a maioria dos médicos da rede básica de serviços de saúde de Paulínea reconheça, pelo menos a nível teórico, a necessidade de se adotar uma atitude didática junto à clientela, eles admitem que, na prática, ela produz resultados pouco satisfatórios, deviddo à falta de tempo e de recursos humanos preparados para lidar com este tipo de problema. Os médicos particulares e de convênios, além dos farmacêuticos, concorrem para dificultar a implantação desta proposta, na medida em que estimulam a hospitalização e o consumo de medicamentos químicos industrializados.

\section{As Farmácias e os Farmacêuticos}

As 14 farmácias do município, as quais oferecem uma média de 30 consultas por dia, são instâncias importantes de atenção médica prestada à população. Em geral, estes estabelecimentos têm se mostrado um negócio próspero, com o proprietário da farmácia - o farmacêutico - posicionando-se socialmente como de classe média alta e disfrutando de prestígio social e político no município. $\mathrm{O}$ faturamento médio mensal das maiores chega a 350 salários mínimos, um número que, nos últimos anos, vem crescendo constantemente em 
termos reais. Os empregados com experiência em diagnóstico e tratamento de doenças são disputados pelo mercado e chegam a ganhar mais de 10 salários mínimos por mês. Entre estas farmácias, cinco são procuradas mais intensamente pela população estudada.

De modo geral, uma importante fonte de lucro destes estabelecimentos é a venda de medicamentos de laboratórios menores, considerados pouco sérios, que, para competir com os laboratórios maiores, considerados sérios, oferecem ao farmacêutico uma margem de lucro muito mais ampla. Quase todos os farmacêuticos acusam-ssse mutuamente de recorrer a este expediente, considerado inescrupuloso.

Praticamente todos os proprietários de farmácias atribuíram o fato de oferecerem consulta médica a uma questão humanitária da qual não poderiam se esquivar, diante da ineficácia dos serviços públicos de saúde e do sofrimento dos pacientes, apesar de todos reconhecerem ser esta uma atividade ilegal. Embora ilegal, não houve qualquer receio ou constrangimento em revelá-la de modo surpreendentemente franco.

O conflito com os médicos da rede pública de serviços de saúde é generalizado, sendo bem expresso por um dos farmacêuticos entrevistados:

\section{- "O problema dos médicos do Centro e} dos Postos de Saúde é que eles esperam demais, deixando o paciente muito tempo em observação, sem medicamento. Quando o caso se agrava, muitas vezes não dá mais tempo para curar. Quando receitam, os médicos só recorrem ao AAS e ao soro. As mães não se conformam em levar o filho doente para casa só com uns comprimidos de AAS na mão e, por isso, passam na farmácia no caminho de casa. Lá eu costumo examinar bem o paciente e receito o remédio necessário. O problema é que os médicos do Centro de Saúde são quase todos estudantes da Unicamp, mocinhos muito jovens, sem experiência alguma".

É evidente que o procedimento de evitar a medicação desnecessária do paciente contraria $o$ interesse na venda de medicamentos, ilustrando uma postura dissonante e disfuncional dos médicos da rede pública com relação ao sistema médico dominante, baseado no hospital e na indústria farmacêutica. É curioso observar, neste sentido, que os médicos da rede pública não constituem uma alternativa moderna e eficiente que se contrapõe aos farmacêuticos tradicionais e ineficientes. Na verdade, são estes últimos que se mostram em consonância com os interesses dominantes da sociedade. Temos, portanto, em Paulínea, uma situação em que aspectos tradicionais, representados pelo papel desempenhado pelo farmacêutico, adaptam-se no sentido não só de servir à medicina capitalista dominante, mas também de expressá-la.

\section{A Avaliação dos Médicos e Farmacêuticos pela População}

Os serviços públicos de saúde em geral recebem três tipos de avaliação por parte da população estudada: uma totalmente positiva, uma totalmente negativa e uma que os considera um recurso positivo disponível à população, mas que apresenta falhas em vários aspectos.

Esta última avaliação é a que predomina, correspondendo a aproximadamente $60 \%$ dos casos, sendo que os $40 \%$ restantes distribuim-se de modo equilibrado entre as duas outras avaliações. O Centro de Saúde e o Pronto-Socorro apresentam uma avaliação mais favorável, devido aos seus recursos mais sofisticados e à maior capacidade de intervenção médica. Já o Hospital da Unicamp, para onde são encaminhados os casos que exigem uma intervenção mais complexa, é considerado excelente, sendo que a grande maioria deixa-se impressionar favoravelmente pela alta tecnologia disponível nesta instituição.

A tendência dos médicos em dizer que, na maior parte dos casos, o paciente não tem nada sério, evitando medicá-lo com remédios fortes quando não consideram necessário, foi o principal ponto levantado para justificar uma avaliação negativa dos Postos de Saúde. A população procura uma solução individual e rápida, no sentido de recompor a força de trabalho e a capacidade de sobrevivência. Ter a certeza de que alguma providência está sendo tomada para se atingir estes objetivos é indispensável para que o paciente assuma uma postura positiva diante do tratamento. Para este propósito, ingerir alguns medicamentos várias vezes ao dia, imaginando que eles possam combater a 
doença, gera confiança. Por outro lado, receber a mensagem de que não há nada que se possa fazer, a não ser esperar a evolução da doença, gera incerteza, dúvida e intranqüilidade, uma condição que, reconhecidamente, não é muito propícia para o restabelecimento da saúde.

A insatisfação da clientela quantoo aos serviços prestados pela rede pública de saúde tem muito a ver com o fato de a mesma sentir-se frustrada em sua expectativa de uma intervenção ativa do médico no sentido de restabelecer a sua saúde como num passe de mágica. $\mathrm{O}$ mecanismo, neste caso, não difere de qualquer ritual de cura, como ocorre pelo relato de vários etnólogos em diversos contextos sociais. Para ser eficaz, o rito deve ser executado em consonância com certos símbolos que garantam competência e poderes sobrenaturais daquele que o executa. Um erro na fórmula ou uma inadequação nos símbolos executados produz um fracasso em seus propósitos. De certa maneira, para grande parcela da população, os médicos dos Postos e Centro de Saúde agem de modo a não se conformarem com o ritual necessário para promover a cura.

Outro ponto negativo nesta avaliação refere-se ao fato de alguns médicos terem o aspecto muito jovem, com aparência de estudantes e com atitudes que não simbolizam o seu status, como, por exemplo, o fato de usarem barba e não vestirem roupa branca típica de médico. A delegação de alguns serviços tradicionalmente executados pelos médicos a enfermeiras, auxiliares e atendentes de enfermagem é uma outra questão negativa aos olhos da comunidade. $\mathrm{O}$ choque expressado pelos pacientes que, contrariando suas expectativas, foram atendidos por uma atendente de enfermagem é equivalente ao de um católico tradicional que visse um sacristão, e não um padre, rezar a missa.

Esta avaliação negativa dos Postos de Saúde não compromete em nada o prestígio da medicina ocidental moderna (que é colocada no topo em relação a qualquer outro tipo de tratamento médico), como também não chega propriamente a abalar o prestígio do médico, que detem uma primazia entre todos os outros agentes de cura, oficiais e não-oficiais. Se, no entanto, um médico não corresponde ao papel social que espera-se dele, é freqüente, nas representações sociais sobre ele, rebaixá-lo à condição de estudante, da mesma forma como alguns dos farmacêuticos são promovidos à condição de médicos ou quase médicos justamente por preencherem o papel que espera-se deste tipo de agente. Neste processo, as representações culturais da população, inclusive a representação extremamente positiva da medicina oficial, são protegidas e preservadas.

O grande prestígio popular usufruído por dois farmacêuticos a quem a população estudada recorre e o status ambíguo desfrutado por um número significativo de médicos da rede pública de serviços de saúde mostram, de modo eloqüente, que o ato médico não é meramente técnico. Ele é, de fato, um ato simbolicamente carregado, por serem inevitáveis sua tradução ao código e sua adequação aos símbolos socialmente significativos da comunidade.

\section{AS ESTRATÉGIAS NO CONSUMO DE AGENTES DE SAÚDE E DE MEDICAMENTOS}

Num mercado com configuração capitalista, o consumo em saúde decorre de um complexo coonjunto de elementos de decisão, valores, representação, padrões culturais e práticas individuais, familiares e de classe social. As estratégias de consumo utilizam-se de elementos de diferentes sistemas de cura e de diferentes agentes e situações dentro de cada sistema, que, por sua vez, são influenciados pelo padrão de desenvolvimento econômico e social vigente na sociedade mais ampla. Fatores gerais, tais como as condições de produção da oferta, o padrão de distribuição de renda, as políticas governamentais e a pertinência a classes e estratos sociais, imprimem uma influência fundamental na organização do consumo.

De modo geral, pode-se dizer que, apesar da situação privilegiada de Paulínea em relação aos demais municípios brasileiros, os bens e serviços de saúde são consumidos dentro de um contexto de carência social, cultural, econômica e de saúde em que vive a maior parte da população. Neste contexto inserem-se os apelos de consumo movidos por interesses discrepantes, como é o caso dos Postos de Saúde, de um lado, e dos farmacêuticos e da medicina privada e conveniada, de outro. No meio destes dois 
pólos ainda convivem as tradições de cura religiosa e a medicina caseira, baseada em ervas medicinais.

Como um elo central que coordena, manipula e administra as estratégias de consumo encontra-se a família, que, em última instância, controla os passos necessários para a decisão sobre o que consumir. Cabe à mãe ou à dona de casa decidir se algum membro da família está doente, qual a gravidade da doença e se este deve receber algum tipo de tratamento. O fator econômico é, sem dúvida, o mais importante na determinação da tomada de decisão. Este fator configura e limita o universo de opções e o leque de possibilidades disponíveis. Outros fatores também desempenham um papel importante nas estratégias desenvolvidas pelas famílias, destacando-se a situação e as condições da oferta de serviços públicos de saúde.

Entre as famílias trabalhadoras de Paulínea, um paciente tende a se mover da medicina oficial para a medicina popular com grande facilidade. Dentro da medicina ofical, da mesma forma, a mobilidade entre a sua versão pública para a versão privada é grande. Dentro da medicina pública, move-se também entre os vários médicos. A mesma mobilidade ocorre dentro do âmbito da medicina popular.

Neste contexto, o campo de ação de um paciente é análogo ao de um mercado onde se oferecem diferentes produtos confeccionados sob diferentes paradigmas e propostas ideológicas de cura e onde, embora a medicina represente um valor inquestionável, o comprometimento com ela é parcial e limitado pela concorrência com outras alternativas (Bourdieu, 1974; Beals, 1976).

Neste sentido, muitas vezes o tratamento médico é realizado apenas de forma parcial; outras vezes não é realizado de todo; e, outras vezes ainda, é realizado a partir de iniciativas não-médicas, baseadas em experiências prévias de vizinhos, parentes, conhecidos ou do próprio paciente. Qualquer que seja o caso, o risco para a saúde é real, principalmente quando o tratamento envolve medicamentos químicos e é realizado sem orientação competente.

Neste esquema, o médico significa apenas uma peça entre outras num tabuleiro complexo que, em última instância, é manipulado pela população. Mesmo os médicos do setor público que, em sua prática, procuram educar e aconselhar seus clientes em questões relativas à saúde pouco podem fazer para alterar a situação numa escala um pouco maior. Isso porque vários fatores que encontram-se fora do seu controle, relativos à situação sócio-econômica e cultural do paciente, incidem poderosamente sobre o problema.

Uma importante variável que contribui para colocar o paciente ainda mais distante do controle médico-profissional é a possibilidade sempre presente de se adquirir medicamentos poderosos, como os antibióticos, sem nenhum tipo de restrição, em qualquer uma das farmácias existentes no município. A proporção de pessoas que efetivamente compram este tipo de medicamento sem nenhuma orientação que mereça crédito é grande, apesar dos esforços em contrário dos Postos de Saúde.

Assim, no tocante ao consumo de medicamentos, vale a pena lembrar o estudo de Haak (1988), cujas conclusões principais encontramse em perfeita consonância com este trabalho. Neste estudo, realizado em duas aldeias rurais da Bahia, o autor destaca a importância do farmacêutico (prático de farmácia) como estímulo fundamental à automedicação descontrolada. Com isso, toda a população se expõe ao consumo de drogas, o que, na melhor das hipóteses, é irracional e, na pior, pode se tornar num verdadeiro perigo para a saúde. A situação em Paulínea só não chega a ser tão dramática principalmente porque a rede pública de serviços de saúde conseguiu um certo número de adeptos na sua visão de medicina, que procura restringir drasticamente o uso de medicamentos.

\section{DISCUSSÃO GERAL}

Como vimos, enquanto os médicos privados e os farmacêuticos tendem a aceitar plenamente a condição auto-imposta de doente por parte do cliente, medicando-o mesmo quando sabem que ele não apresenta morbidade alguma, os médicos do serviço público tendem a não medicá-lo quando percebem que o caso não pode ser resolvido adequadamente à base de medicamentos. Não deixa de ser um paradoxo, no entanto, o fato de os médicos da rede pública, que 
consideram extremamente importantes os aspectos sociais e econômicos na origem e na manifestação das doenças, não utilizarem esse mesmo parâmetro no tratamento e na cura. A resistência ao uso indiscriminado de medicamentos, o não-uso de roupas brancas e o nãoemprego de símbolos socialmente significativos, como, por exemplo, a exibição de aparelhos tecnologicamente complicados, são aspectos desta atitude que desconsidera o lado simbólico como parte importante no processo de cura.

De modo geral, os médicos da rede pública estão cientes das dificuldades que impedem uma melhor comunicação com a comunidade. No entanto, como o objetivo principal não é obter a aprovação de seus clientes a qualquer custo, eles mostram pouca disposição em transigir naquilo que acreditam ser o aspecto principal da missão que desempenham, ou seja, o caráter educativo do que consideram uma prática descompromissada com relação ao caráter capitalista da medicina. No entanto, ao manter esta atitude insensível à cultura da comunidade, eles correm o risco de serem considerados pela mesma incompetentes para diagnosticar e tratar doenças. Ao ceder a este tipo de tentação, por outro lado, eles correm o risco de se comprometerem com interesses alheios ao seu ideal. É inevitável, para eles, a convivência com este tipo de dilema.

A população, por sua vez, não vê vantagem alguma em saber que a origem de grande parte dos seus problemas de saúde encontra-se nas condições sócio-econômicas e culturais de vida e que a medicina muito pouco pode fazer para tratá-los, a não ser mostrar que eles existem. A população reivindica soluções práticas que permitam, sobretudo, um restabelecimento rápido às condições normais de vida e de trabalho. $\mathrm{O}$ intervencionismo médico, ligado a uma tecnologia hospitalar especializada, consiste num forte apelo neste sentido.

Levando-se em consideração as condições de carência econômica, social e cultural da população e a ausência de um passado coerente e racional no seu relacionamento com os serviços médicos, seria necessário um esforço muito maior por parte dos serviços públicos de saúde para acelerar um processo de educação da população, no sentido de contrabalançar a influência dos farmacêuticos e de médicos da rede privada, todos eles interessados numa supermedicação. Além da educação, seria necessário também o cumprimento de uma legislação rigorosa na fabricação e venda de medicamentos, algo que depende de vontade política do governo.

O papel dos Postos de Saúde é, e deve ser, desmistificar esta crença em magia e restabelecer uma imagem mais verdadeira sobre o papel da medicina numa comunidade. É difícil dizer até que ponto isto está sendo conseguido. Certamente, alguns entrevistados absorveram admiravelmente esta proposta e adotaram uma postura mais realista diante da doença. No entanto, a maioria das entrevistas revela um outro quadro, ou seja, indivíduos que, diante de problemas de saúde, ainda se perdem num emaranhado irracional de propostas de cura, quase todas elas destituídas de consistência, por serem parciais e sem vistas às dimensões mais abrangentes de vida.

Um aspecto importante desta inconsistência refere-se à dificuldade de haver um acompanhamento clínico do paciente por parte de cada agente de cura. Numa população de imigração recente, proveniente de vários pontos do país, o ato médico quase sempre ainda se faz sem uma análise da história clínica do paciente. A manipulação, por parte do paciente, das várias instituições que prestam serviços de cura, dos vários sistemas de cura e dos vários agentes de cura evidentemente não contribui para que haja este tipo de acompanhamento.

A integração dos serviços públicos de saúde num sistema único está inegavelmente trazendo alguma racionalidade ao sistema de prestação de serviços médicos. A sua proposta mais abrangente de medicina também contribui para esclarecer a população sobre os riscos e os benefícios que o tratamento médico inevitavelmente produz. Para que esta proposta se consolide, no entanto, é necessário que ocorram várias mudanças relativas à produção e ao consumo do ato médico, além, evidentemente, do desenvolvimento social, econômico e cultural do país como um todo. 


\section{RESUMO}

QUEIROZ, M. S. Estratégias de Consumo em Saúde entre Famílias Trabalhadoras.

Cad. Saúde Públ., Rio de Janeiro, 9 (3): 272282, jul/set, 1993.

O presente artigo analisa as representações e as práticas sobre saúde e doença entre famílias operárias do município de Paulínea, São Paulo. Ênfase especial é colocada no relacionamento desta população com a medicina posta em prática pela rede pública de atenção à saúde, recentemente implantada no município e considerada modelo no contexto brasileiro pelos técnicos do setor. As práticas relacionadas com as medicinas caseira e religiosa e com os farmacêuticos, bem como o problema da automedicação, são também focalizadas como elementos importantes disponíveis à população estudada.

Palavras-Chave: Representações sobre Saúde e Doença; Cuidados Primários de Saúde;

Saúde Do Trabalhador; Serviços de Saúde

\section{REFERÊNCIAS BIBLIOGRÁFICAS}

BEALS, A. R., 1976. Strategies of resort to curers in South India. In: A sian Medical Systems (C. Leslie, ed.), pp. 72-97, Berkeley: University of California Press.

BOLTANSKI, L., 1979. As Classes Sociais e o Corpo. Rio de Janeiro: Graal.

BOURDIEU, P., 1975. A Economia das Trocas Simbólicas. São Paulo: Perspectiva.
FOSTER, G. M., 1976. Diseases etiologies in nonwestern medical systems. American Anthropology, 78: 78-94.

GIOVANI, G., 1980. A Questão dos Remédios no Brasil. São Paulo: Polis.

HAAK, H., 1988. Pharmaceuticals in two brazilian villages: lay practices and perceptions. Social Sciences and Medicine, 27: 1415-1427.

D'HAUTAND, A. \& FIELDMAN, M. G., 1984. The image of health: variations in perception by social class in a french population. Sociology of Health and IIIness, 6: 147-158.

MONTERO, P., 1985. Da Doença à Desordem: a Magia da Umbanda. Rio de Janeiro: Graal.

QUEIROZ, M.S. 1984. Hot and cold classification in traditional Iguape medicine. Ethnology, 23: $63-72$

, 1991. Representações Sobre Saúde e Doença: Agentes de Cura e Pacientes no Contexto do SUDS. Campinas: Editora da Unicamp.

WEBER, M., 1969. The Sociology of Religion. Londres: Methuen. 